\title{
Brown Adipose Tissue as a Therapeutic Target for Obesity: From Mice to Humans
}

Masayuki Saito*

Hokkaido University, Sapporo, Japan

Brown adipose tissue (BAT) is a site of sympathetically activated non-shivering thermognenesis during cold exposure and after spontaneous hyperphagia, thereby involving in the autonomic regulation of energy balance and body fatness. Recent radionuclide studies have demonstrated the existence of metabolically active BAT in adult humans. Human BAT is activated by acute cold exposure, particularly in winter, and contributes to cold-induced increase in whole-body energy expenditure. The metabolic activity of BAT is lower in older and obese individuals. The inverse relationship between the BAT activity and body fatness suggests that BAT, because of its energy dissipating activity, is protective against body fat accumulation. In fact, either repeated cold exposure or daily ingestion of some food ingredients acting on transient receptor potential channels recruited BAT in association with increased energy expenditure and decreased body fatness. Thus, BAT is a promising target for combating obesity and related metabolic disorders in humans.

Key words: Brown adipose tissue, Cold exposure, Energy expenditure, FDG-PET/CT, Obesity, Transient receptor potential channel

\section{Background}

Obesity and related metabolic disorders are worldwide epidemics. As obesity is the state of excessive accumulation of body fat because of prolonged positive energy balance, it can be treated by reducing food intake and/or increasing energy expenditure (EE). For the latter, increasing attention has currently been paid on brown adipose tissue (BAT), a specific site for non-shivering thermogenesis to dissipate energy as heat. ${ }^{1,2}$ This is because of several remarkable advancements in BAT research over the last few years. Particularly, being against the conventional view that human BAT is functional only in neonates, recent radionuclide imaging studies have revealed the existence of a considerable amount of BAT in adult humans. ${ }^{3-6}$ There are now piles of evidence suggesting BAT as a significant regulatory site of whole-body EE and body fatness not only in small rodents but also in humans..$^{7-9}$ Moreover, recent prospective studies in humans confirmed that activation and recruitment of BAT actually increases EE and decreases body fatness. ${ }^{10-12}$ Thus, BAT may be a promising target for combating obesity and related metabolic disorders. This review summarizes the regulatory mechanisms of BAT thermogenesis in mice and humans, and discusses its therapeutic potential for combating obesity.

\section{Mechanism and physiological roles of BAT thermogenesis}

BAT is a unique adipose tissue, of which function is metabolic thermogenesis to produce energy in the form of heat. Significant amounts of BAT are found in small rodents and hibernators, being essential for the survival in cold environment and for arousal from hibernation. BAT has also been proposed to be involved not only in cold-induced non-shivering thermogenesis but also in diet-induced thermogenesis, and to play a role in the regulation of EE, whole-body energy balance, and body fatness. This is supported by various lines of observation, particularly, that mice with genetically ablated BAT show decreased EE and diet-induced obesity ${ }^{13-15}$, and that activation and recruitment of BAT by various physiological and pharmacological stimuli give rise to consistent reduction of body fatness. ${ }^{16-18}$ Thus, it is undoubted, at least in small rodents, that impaired thermogenesis by BAT is one of the causes of obesity.
Corresponding author Masayuki Saito

Hokkaido University, Nishi-ku, Hassamu 16-2-1-32, Sapporo 063-0836, Japan Tel +81-11-664-7918 Fax +81-11-664-7918

E-mail saito@tenshi.ac.jp, ms-consa@krf.biglobe.ne.jp
Copyright (C) 2015 Korean Society for the Study of Obesity

(c) This is an Open Access article distributed under the terms of the Creative Commons Attribution Non-Commercial License (i://creativecommons.org/licenses/by-nc/3.0/) which permits unrestricted non-commercial use, distribution, and reproduction in any medium, provided the original work is properly cited. 
BAT thermogenesis is totally dependent on uncoupling protein 1 (UCP1), which is expressed selectively in mitochondria of brown adipocyte, but not in other types of cell including white adipocyte. UCP1 has the activity to uncouple oxidative phosphorylation from ATP synthesis, thereby dissipating energy as heat. UCP1-dependent BAT thermogenesis is directly regulated by sympathetic nerves distributed abundantly to this tissue: that is, noradrenalin released from the sympathetic nerve endings stimulates the $\beta$-adrenoceptor ( $\beta \mathrm{AR}$ ) signaling cascade, leading hydrolysis of intracellular triglyceride by activating hormone-sensitive and adipose triglyceride lipases (Fig. 1). The released fatty acids activate UCP1 and are oxidized in mitochondria to serve as an energy source of thermogenesis. Fatty acids from blood circulation are also used under some physiological conditions. While the principal substrate for BAT thermogenesis is fatty acids, glucose utilization is also enhanced greatly in parallel with UCP1 activation, probably for sufficient supply of oxaloacetate to enable rapid oxidation of fatty acids and acetyl CoA, and also for rapid

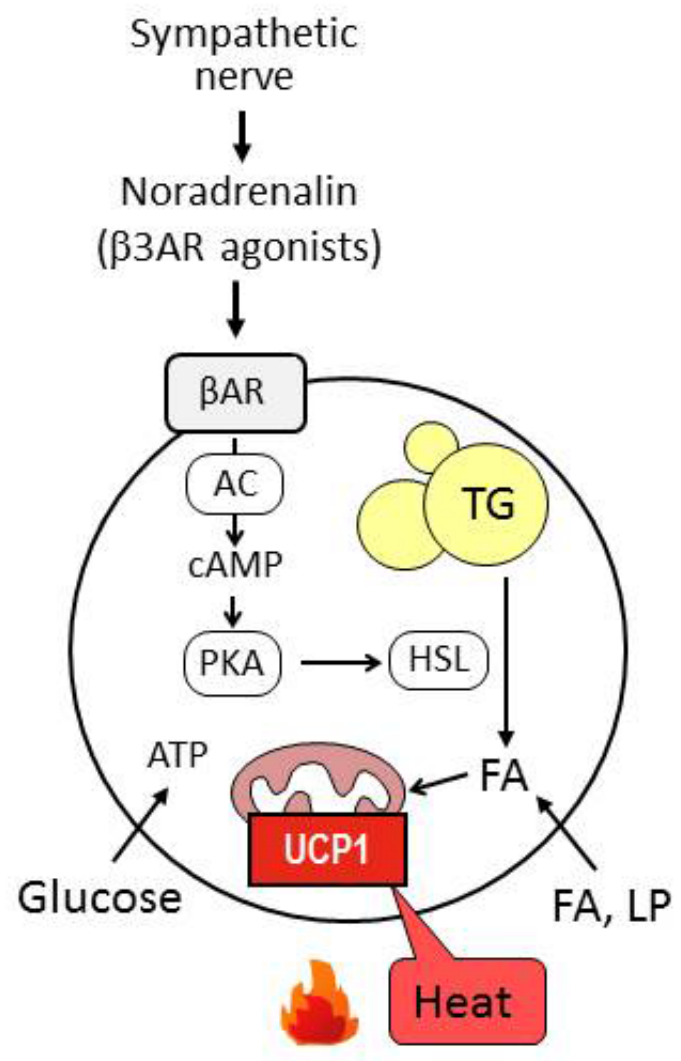

Fig. 1. Sympathetically activated thermogenesis in brown adipose tissue (BAT). $\beta A R$, $\beta$-adrenoceptor; AC, adenylate cyclase; cAMP, cyclic AMP; FA, fatty acids; HSL, hormone-sensitive lipase; LP, lipoprotein; PKA, CAMP-dependent protein kinase; TG, triglyceride. recovery of cellular ATP levels by activating anaerobic glycolysis. ${ }^{19}$ Thus, UCP1-dependent glucose utilization is a metabolic index of BAT thermogenesis, and has been applied for assessing human BAT as noted in the latter section.

There are two types of UCP1-positive thermogenic adipocyte. ${ }^{2,20}$ The major BAT depot in small rodents is found in the interscapular region. Adipocytes in this depot originate from Myf5-positive myoblastic cells that also give rise to skeletal muscle cells, and are called "classical brown adipocytes". UCP1-expressing adipocytes also develop in fat depots usually considered as white adipose tissue (WAT) after prolonged cold exposure or repeated administration of sympathomimetics including $\beta 3 \mathrm{AR}$ agonists. ${ }^{21,22}$ These adipocytes, named "beige or brite adipocytes", arise from developmentally distinct lineages from classical brown adipocytes; they originate from a Myf5negative precursor cells. Recent studies have indicated that beige/ brite adipocytes have comparable thermogenic activity to classical brown adipocytes and contribute significantly to the regulation of body fatness. $^{23,24}$

\section{Regulation of brown/beige adipocytes}

As briefly summarized above, the sympathetic nerve and $\beta A R$ system is a central regulator of brown and beige/brite adipocytes. This system is activated by various external stimuli, the most typical of which is cold exposure. The principal role of this system for BAT thermogenesis was confirmed by a finding that mice lacking $\beta$-AR as well as those lacking UCP1 are unable to maintain body temperature under a cold environment and die in couples of hour. ${ }^{13,25}$ It is also known that prolonged cold exposure or repeated administration of $\beta$ AR agonists causes hyperplasia of BAT by increased proliferation of classical brown adipocyte and also induction of beige adipocytes in WAT. ${ }^{21,22}$

In addition to or in combination with this system, some hormones and factors have been identified as activators/recruiters of BAT (Fig. 2). ${ }^{26}$ A representative is triiodothyronine (T3), which is well known as a potent transcriptional activator of the UCP1 gene. ${ }^{27}$ It is to be noted that $\mathrm{T} 3$ in BAT is produced from thyroxine by the action of type II deiodinase (D2), which is activated in response to sympathetic stimulation. D2 in BAT is also shown to be activated by bile acids coming from the liver. ${ }^{28}$ There have been reports demonstrating significant roles of heart derived natriuretic peptides (NP), well-known regulators of fluid and hemodynamic homeostasis, in BAT recruit- 
ment. NP enhances whole-body EE, probably due to an up-regulation of UCP1 in BAT and induction of WAT browning via the cyclic GMP and p38MAP-kinase signaling cascade. ${ }^{29}$

Currently, much attention has been paid on the mechanism for induction of beige adipocye. Qiu et al. ${ }^{30}$ reported that functional beige adipocytes are induced by noradrenalin released from macrophages that are alternatively activated by eosinophils. Critical roles of esosinophils and type 2 cytokine signaling in macrophage were also shown in the action of meterorin-like, a circulating factor induced in muscle after exercise and in adipose tissue upon cold exposure, which stimulates WAT browning and EE. ${ }^{31}$ The involvement of alternative activation of macrophages in the induction of thermogenic beige fat is a quite contrast with that of classical activation of macrophages, which is closely associated with metabolic and endocrine disorders of WAT. Fibroblast growth factor 21, a liver-derived endocrine factor, is potential for inducing the thermogenic program in BAT and WAT browning, and also for reducing body fatness. ${ }^{32}$

\section{Human BAT detected by FDG-PET/CT}

Most information about BAT mentioned above has come from studies using small rodents such as mice, rats, and hamsters. In larger mammals including humans, anatomical and histological studies have reported that BAT is present only in neonates, but disappears rapidly during postnatal periods. ${ }^{33}$ However, the existence of metabolically active BAT in adult humans has been demonstrated by the studies using fluoro-deoxyglucose (FDG)-positron emission tomography (PET) combined with computed tomography (CT): that is, PET/CT sometimes detects symmetrical FDG uptake in adipose tissue at the shoulder and thoracic spine regions. Such FDG uptake is substantially increased after cold exposure or administration of $\beta \mathrm{AR}$ agonists $^{34}$, but reduced by pretreatment with $\beta$-adrenergic blockers. ${ }^{35}$ As $\beta$-adrenergically stimulated 2-deoxyglucose uptake into BAT is totally dependent on the activation of $\mathrm{UCP}^{19}$, the observations by PET/CT collectively suggest that the FDG uptake in adipose tissue at the specific regions reflects the metabolic activity of BAT. In fact,
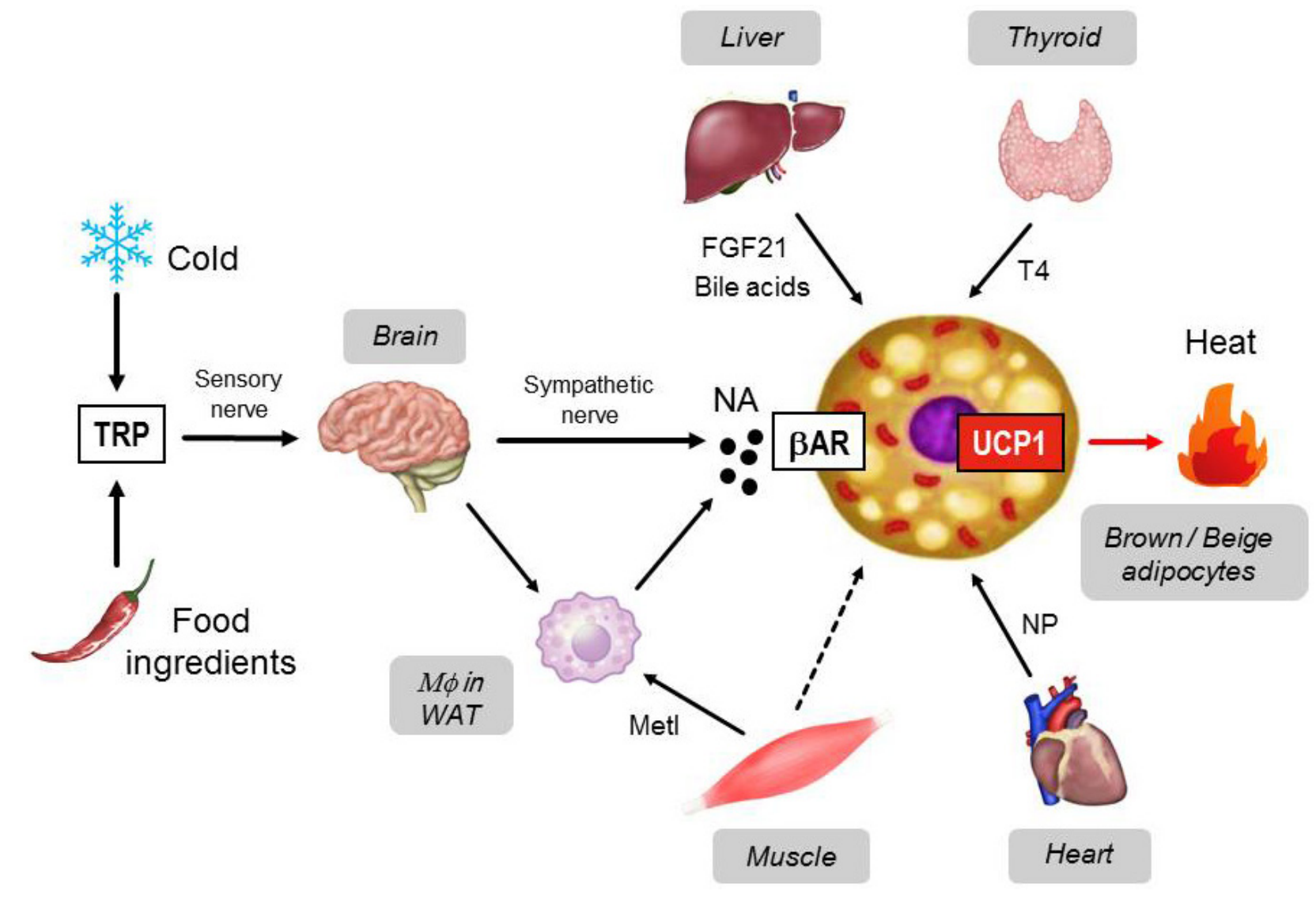

Fig. 2. Factors acting on brown/beige adipocytes.

$\beta A R$, $\beta$-adrenoceptor; FGF21, fibroblast growth factor 21; Metl, meteorin-like; Mф, macrophage; NA, noradrenalin; NP, natriuretic peptide; TRP, transient receptor potential; T4, thyroxine; WAT, white adipose tissue. 


\begin{tabular}{|c|c|c|}
\hline FDG uptake into BAT & Low & High \\
\hline Thermogenesis & Low & High \\
\hline Temperature & Warm & Cold \\
\hline Season & Summer & Winter \\
\hline$\beta$-Adrenoceptor & Antagonist & Agonist \\
\hline Age & Old & Young \\
\hline Fatness & Obese & Lean \\
\hline
\end{tabular}

Fig. 3. Human brown adipose tissue (BAT) detected by FDG-PET/CT. Fluorodeoxyglucose (FDG) uptake into adipose tissue at the supraclavicular and paraspinal regions is detected by positron emission tomography (PET). FDG uptake into BAT, which reflects the thermogenic activity, is influenced by various external and internal factors.

histological examinations revealed the presence of UCP1-positive adipocytes in these regions. ${ }^{3-6}$ Expression analysis of some marker genes has shown that BAT in the shoulder region of adult humans is largely composed of beige adipocytes more than classical brown adipocytes. ${ }^{22,36,37}$

The activity and prevalence of BAT detected by FDG-PET/CT in adults are influenced by various exogenous and endogenous factors (Fig. 3). The prevalence is less than $10 \%$ in most retrospective clinical studies, whereas it is $30-100 \%$ in dedicated studies for healthy volunteers. ${ }^{2,8}$ Such apparent discrepancy is largely due to the different temperatures at the FDG-PET/CT scanning: in dedicated studies it is performed after acute cold exposure at $16-19^{\circ} \mathrm{C}$ for $1-2$ hours, whereas retrospective studies are mostly performed at room temperatures $\left(22-26^{\circ} \mathrm{C}\right)$ without cold exposure. Acute cold exposure increases FDG uptake into BAT, giving a high prevalence of BAT detection. Indeed, no BAT signals were detected at $27-28^{\circ} \mathrm{C}$ even in subjects who showed high BAT activities after cold exposure. Moreover, the prevalence and activity of BAT are also influenced by outdoor temperature and show seasonal variations, being higher in winter than in summer even in the same subjects. ${ }^{3}$ This suggests that human BAT is a reversibly convertible tissue: in other words, it is inducible by environmental stimuli such as daily cold exposure. In fact, repeated cold exposure results in an induction of BAT in subjects who have undetectable BAT before the cold exposure. ${ }^{10-12}$

The prevalence and activity of BAT are substantially modulated with age. Our study for healthy participants aged 20-73 years demonstrated that the prevalence of cold-activated BAT was more than $50 \%$ in young subjects of the twenties, decreased with age, and in less than $10 \%$ of the fifties and sixties. ${ }^{38,39}$ A strong impact of age on BAT prevalence has also been reported in clinical studies. ${ }^{40-43}$ We found that polymorphism of some genes including UCP1 and $\beta 3 A R$ accelerates the age-related decrease in BAT activity. ${ }^{44}$ Recently, Bakker et al. $^{45}$ reported larger BAT volume in healthy lean Caucasians than age-matched south Asians. These findings indicate a significant impact of genetic factors on human BAT.

\section{Activation and recruitment of BAT as an anti-obesity regimen in humans}

The presence of cold-activated BAT suggests a contribution of BAT to cold-induced thermogenesis. In fact, it has been confirmed that whole-body EE after cold exposure is greater in subjects with higher BAT activities, showing a positive correlation between the BAT activity and cold-induced thermogenesis. ${ }^{10,46-48}$ Moreover, retrospective readings of FDG-PET/CT in thousands of patients and dedicated studies in healthy participants have demonstrated that the activity and prevalence of BAT are inversely related to body fatness assessed by mass index (BMI), body fat content, and visceral fat. ${ }^{3,4,39-43}$ Collectively, it is conceivable that BAT, because of its energy dissipating activity, is protective against body fat accumulation in humans as it is in small rodents.

This has encouraged the search how to activate or recruit BAT, which is particularly intriguing because people with lower or undetectable BAT activities are more obese and to be treated. As noted previously, cold seems the most physiological and powerful stimulus for BAT activation. In addition to the acute stimulatory effects of cold on BAT, prolonged cold exposure produces not only BAT hyperplasia but also a remarkable induction of beige adipocytes, both of which contribute to increased $\mathrm{EE}$ and reduced body fatness. Recent studies have confirmed that this is also true in humans. ${ }^{10-12}$ For example, when subjects with undetectable or low BAT activity were kept in a cold environment at $17^{\circ} \mathrm{C}$ for 2 hours every day for 6 weeks, their BAT activity was significantly increased. ${ }^{10}$ More importantly, the change in BAT activity was positively and negatively correlated with those in cold-induced thermogenesis and body fat content, respectively (Fig. 4).

Although daily cold exposure can recruit human BAT, it would 
A

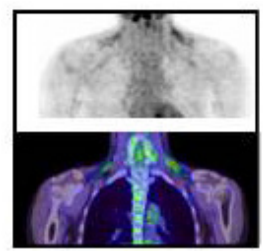

0 week

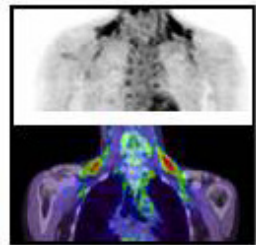

6 weeks
B $\Delta E E(K c a l / d a y)$

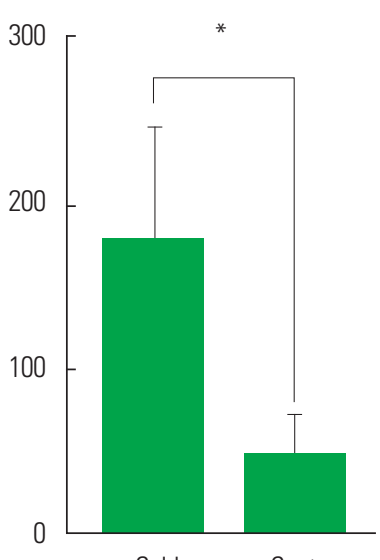

Cold

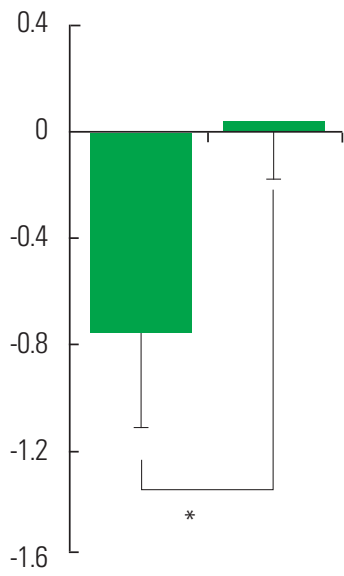

Cold
C $\Delta$ Body fat $(\mathrm{kg})$

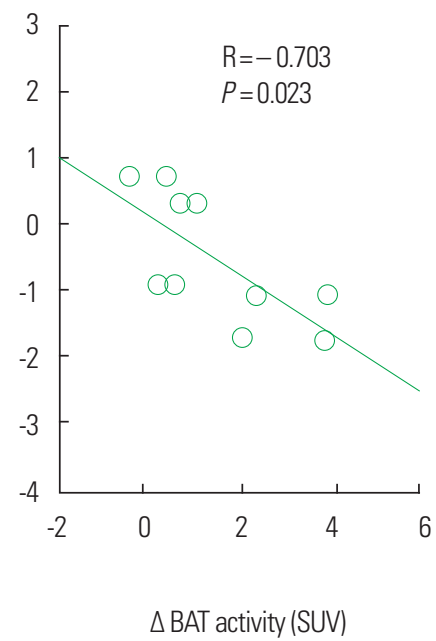

Fig. 4. Effects of repeated cold exposure on brown adipose tissue (BAT), energy expenditure, and body fatness. Healthy male subjects were exposed to cold at $17^{\circ} \mathrm{C}$ for 2 hours every day for 6 weeks and underwent fluorodeoxyglucose (FDG) -PET/CT (A). The changes in energy expenditure (B) and body fat content (C) during the 6 weeks period were compared with those kept at room temperature (Cont). The change in body fat content was correlated with that of BAT activity (C).

seem difficult to increase exposure to cold in daily life. It is now well established that cold stimulus is received by transient receptor potential channels (TRP). Among the members of the TRP family, TRPM8 and TRPA1 are the most likely receptor candidates sensitive to low temperatures. ${ }^{49}$ Accordingly, chemical activation of these receptors would mimic the effects of cold exposure (Fig. 2). There are various food ingredients acting as agonists for these TRPs ${ }^{50}$, a representative of which is menthol, a cooling and flavor compound in mint, acting on TRPM8. In fact, Ma et al. ${ }^{51}$ demonstrated in mice that dietary menthol enhances BAT thermogenesis and prevents high fat diet-induced obesity in a TRPM8-dependent manner. Among the TRP agonists so far reported, the most extensively studied is capsaicin, a pungent principle of chili pepper, which is a potent agonist for TRPV1. Animal studies have demonstrated that capsaicin and its non-pungent analogs (capsinoids) increase BAT thermogenesis through the activation of TRPV1 and the sympathetic nervous system, and decrease body fat. Recent human studies have also confirmed similar BAT-dependent thermogenic and anti-obesity effects of capsinoids. ${ }^{52-54}$ Thus, capsaicin/capsinoids as well as other food ingredients activating the TRP-BAT axis may be promising as anti-obesity regimens easily applicable in daily life.

\section{Conclusion and Perspective}

BAT is now recognized as an important regulatory site of EE and body fatness in not only small rodents but also adult humans. Moreover, recent studies have indicated regulatory roles of BAT for insulinsensitivity, glucose homeostasis, and lipoprotein metabolism ${ }^{12,55-58}$, suggesting that BAT may also be involved in the etiology of diabetes mellitus and dyslipidemias, independently of and/or secondly to obesity. Thus, BAT is a promising target for combating obesity and related metabolic diseases in humans, but there are many issues to be settled. For example, while FDG-PET/CT has widely been used to evaluate BAT in humans, it has serious limitations, including the enormous cost of the devices, radiation exposure, and acute cold exposure, which make repeated FDG-PET/CT difficult and impede both basic and clinical studies. Moreover, it is to be noted that this method provides information for the glucose metabolic activity, rather than that of mass or thermogenic activity of BAT. A less-invasive, simple, and accurate method is needed. Another important issue is to clarify the underlying mechanisms of age-related reduction of BAT, which would be one of the causes for excessive accumulation of body fat in middle-aged individuals. These insights would be a prerequisite for developing feasible and efficient regimens to activate and recruit BAT in obese humans.

\section{Conflicts of Interest}

No potential conflict of interest relevant to this article was reported. 


\section{Acknowledgements}

This work was supported by Grant-in-Aid for Scientific Research from the Ministry of Education, Culture, Sports, Science, and Technology of Japan (22590227, 24240092).

\section{References}

1. Cannon B, Nedergaard J. Brown adipose tissue: function and physiological significance. Physiol Rev 2004;84:277-359.

2. Kajimura S, Saito M. A new era in brown adipose tissue biology: molecular control of brown fat development and energy homeostasis. Annu Rev Physiol 2014;76:225-49.

3. Saito M, Okamatsu-Ogura Y, Matsushita M, Watanabe K, Yoneshiro T, Nio-Kobayashi J, et al. High incidence of metabolically active brown adipose tissue in healthy adult humans: effects of cold exposure and adiposity. Diabetes 2009;58:1526-31.

4. van Marken Lichtenbelt WD, Vanhommerig JW, Smulders NM, Drossaerts JM, Kemerink GJ, Bouvy ND, et al. Cold-activated brown adipose tissue in healthy men. N Engl J Med 2009;360: $1500-8$.

5. Virtanen KA, Lidell ME, Orava J, Heglind M, Westergren R, Nie$\mathrm{mi}$ T, et al. Functional brown adipose tissue in healthy adults. $\mathrm{N}$ Engl J Med 2009;360:1518-25.

6. Cypess AM, Lehman S, Williams G, Tal I, Rodman D, Goldfine $\mathrm{AB}$, et al. Identification and importance of brown adipose tissue in adult humans. N Engl J Med 2009;360:1509-17.

7. Saito M. Brown adipose tissue as a regulator of energy expenditure and body fat in humans. Diabetes Metab J 2013;37:22-9.

8. Lee P, Swarbrick MM, Ho KK. Brown adipose tissue in adult humans: a metabolic renaissance. Endocr Rev 2013;34:413-38.

9. Zafrir B. Brown adipose tissue: research milestones of a potential player in human energy balance and obesity. Horm Metab Res 2013; 45:774-85.

10. Yoneshiro T, Aita S, Matsushita M, Kayahara T, Kameya T, Kawai Y, et al. Recruited brown adipose tissue as an antiobesity agent in humans. J Clin Invest 2013;123:3404-8.

11. van der Lans AA, Hoeks J, Brans B, Vijgen GH, Visser MG, Vosselman MJ, et al. Cold acclimation recruits human brown fat and increases nonshivering thermogenesis. J Clin Invest 2013;123: 3395-403.
12. Lee P, Smith S, Linderman J, Courville AB, Brychta RJ, Dieckmann $\mathrm{W}$, et al. Temperature-acclimated brown adipose tissue modulates insulin sensitivity in humans. Diabetes 2014;63:3686-98.

13. Enerbäck S, Jacobsson A, Simpson EM, Guerra C, Yamashita H, Harper ME, et al. Mice lacking mitochondrial uncoupling protein are cold-sensitive but not obese. Nature 1997;387:90-4.

14. Kontani Y, Wang Y, Kimura K, Inokuma KI, Saito M, Suzuki-Miura T, et al. UCP1 deficiency increases susceptibility to diet-induced obesity with age. Aging Cell 2005;4:147-55.

15. Feldmann HM, Golozoubova V, Cannon B, Nedergaard J. UCP1 ablation induces obesity and abolishes diet-induced thermogenesis in mice exempt from thermal stress by living at thermoneutrality. Cell Metab 2009;9:203-9.

16. Rothwell NJ, Stock MJ. A role for brown adipose tissue in diet-induced thermogenesis. Nature 1979;281:31-5.

17. Lowell BB, Spiegelman BM. Towards a molecular understanding of adaptive thermogenesis. Nature 2000;404:652-60.

18. Inokuma K, Okamatsu-Ogura Y, Omachi A, Matsushita Y, Kimura $\mathrm{K}$, Yamashita $\mathrm{H}$, et al. Indispensable role of mitochondrial UCP1 for antiobesity effect of $\beta 3$-adrenergic stimulation. Am J Physiol Endocrinol Metab 2006;290:E1014-21.

19. Inokuma K, Ogura-Okamatsu Y, Toda C, Kimura K, Yamashita H, Saito M. Uncoupling protein 1 is necessary for norepinephrine-induced glucose utilization in brown adipose tissue. Diabetes 2005; 54:1385-91.

20. Harms M, Seale P. Brown and beige fat: development, function and therapeutic potential. Nat Med 2013;19:1252-63.

21. Guerra C, Koza RA, Yamashita H, Walsh K, Kozak LP. Emergence of brown adipocytes in white fat in mice is under genetic control. Effects on body weight and adiposity. J Clin Invest 1998;102:412-20.

22. Wu J, Boström P, Sparks LM, Ye L, Choi JH, Giang AH, et al. Beige adipocytes are a distinct type of thermogenic fat cell in mouse and human. Cell 2012;150:366-76.

23. Okamatsu-Ogura Y, Fukano K, Tsubota A, Uozumi A, Terao A, Kimura $\mathrm{K}$, et al. Thermogenic ability of uncoupling protein 1 in beige adipocytes in mice. PLoS One 2013;8:e84229.

24. Shabalina IG, Petrovic N, de Jong JM, Kalinovich AV, Cannon B, Nedergaard J. UCP1 in brite/beige adipose tissue mitochondria is functionally thermogenic. Cell Rep 2013;5:1196-203.

25. Bachman ES, Dhillon H, Zhang CY, Cinti S, Bianco AC, Kobilka $\mathrm{BK}$, et al. $\beta \mathrm{AR}$ signaling required for diet-induced thermogenesis 
and obesity resistance. Science 2002;297:843-5.

26. Villarroya F, Vidal-Puig A. Beyond the sympathetic tone: the new brown fat activators. Cell Metab 2013;17:638-43.

27. Bianco AC, McAninch EA. The role of thyroid hormone and brown adipose tissue in energy homoeostasis. Lancet Diabetes Endocrinol 2013;1:250-8.

28. Watanabe M, Houten SM, Mataki C, Christoffolete MA, Kim BW, Sato $\mathrm{H}$, et al. Bile acids induce energy expenditure by promoting intracellular thyroid hormone activation. Nature 2006;439:484-9.

29. Collins S. A heart-adipose tissue connection in the regulation of energy metabolism. Nat Rev Endocrinol 2014;10:157-63.

30. Qiu Y, Nguyen KD, Odegaard JI, Cui X, Tian X, Locksley RM, et al. Eosinophils and type 2 cytokine signaling in macrophages orchestrate development of functional beige fat. Cell 2014;157:1292-308.

31. Rao RR, Long JZ, White JP, Svensson KJ, Lou J, Lokurkar I, et al. Meteorin-like is a hormone that regulates immune-adipose interactions to increase beige fat thermogenesis. Cell 2014;157:1279-91.

32. Fisher FM, Kleiner S, Douris N, Fox EC, Mepani RJ, Verdeguer F, et al. FGF21 regulates PGC-1 $\alpha$ and browning of white adipose tissues in adaptive thermogenesis. Genes Dev 2012;26:271-81.

33. Heaton JM. The distribution of brown adipose tissue in the human. J Anat 1972;112:35-9.

34. Cypess AM, Weiner LS, Roberts-Toler C, Elía EF, Kessler SH, Kahn $\mathrm{PA}$, et al. Activation of human brown adipose tissue by a $\beta 3$-adrenergic receptor agonist. Cell Metab 2015;21:33-8.

35. Nedergaard J, Bengtsson T, Cannon B. Unexpected evidence for active brown adipose tissue in adult humans. Am J Physiol Endocrinol Metab 2007;293:E444-52.

36. Sharp LZ, Shinoda K, Ohno H, Scheel DW, Tomoda E, Ruiz L, et al. Human BAT possesses molecular signatures that resemble beige/ brite cells. PLoS One 2012;7:e49452.

37. Lee P, Werner CD, Kebebew E, Celi FS. Functional thermogenic beige adipogenesis is inducible in human neck fat. Int J Obes (Lond) 2014;38:170-6.

38. Yoneshiro T, Aita S, Matsushita M, Okamatsu-Ogura Y, Kameya T, Kawai Y, et al. Age-related decrease in cold-activated brown adipose tissue and accumulation of body fat in healthy humans. Obesity (Silver Spring) 2011;19:1755-60.

39. Matsushita M, Yoneshiro T, Aita S, Kameya T, Sugie H, Saito M. Impact of brown adipose tissue on body fatness and glucose metabolism in healthy humans. Int J Obes (Lond) 2014;38:812-7.
40. Pfannenberg C, Werner MK, Ripkens S, Stef I, Deckert A, Schmadl $\mathrm{M}$, et al. Impact of age on the relationships of brown adipose tissue with sex and adiposity in humans. Diabetes 2010;59:1789-93.

41. Quellet V, Routhier-Labadie A, Bellemare W, Lakhal-Chaieb L, Turcotte E, Carpentier AC, et al. Outdoor temperature, age, sex, body mass index, and diabetic status determine the prevalence, mass, and glucose-uptake activity of 18F-FDG-detected BAT in humans. J Clin Endocrinol Metab 2011;96:192-9.

42. Zhang Q, Ye H, Miao Q, Zhang Z, Wang Y, Zhu X, et al. Differences in the metabolic status of healthy adults with and without active brown adipose tissue. Wien Klin Wochenschr 2013;125: 687-95.

43. Persichetti A, Sciuto R, Rea S, Basciani S, Lubrano C, Mariani S, et al. Prevalence, mass, and glucose-uptake activity of 18F-FDGdetected brown adipose tissue in humans living in a temperate zone of Italy. PLoS One 2013;8:e63391.

44. Yoneshiro T, Ogawa T, Okamoto N, Matsushita M, Aita S, Kameya $\mathrm{T}$, et al. Impact of UCP1 and $\beta 3 \mathrm{AR}$ gene polymorphisms on agerelated changes in brown adipose tissue and adiposity in humans. Int J Obes (Lond) 2013;37:993-8.

45. Bakker LE, Boon MR, van der Linden RA, Arias-Bouda LP, van Klinken JB, Smit F, et al. Brown adipose tissue volume in healthy lean south Asian adults compared with white Caucasians: a prospective, case-controlled observational study. Lancet Diabetes Endocrinol 2014;2:210-7.

46. Orava J, Nuutila P, Lidell ME, Oikonen V, Noponen T, Viljanen T, et al. Different metabolic responses of human brown adipose tissue to activation by cold and insulin. Cell Metab 2011;14:272-9.

47. Yoneshiro T, Aita S, Matsushita M, Kameya T, Nakada K, Kawai Y, et al. Brown adipose tissue, whole-body energy expenditure, and thermogenesis in healthy adult men. Obesity (Silver Spring) 2011; 19:13-6.

48. Muzik O, Mangner TJ, Leonard WR, Kumar A, Janisse J, Granneman JG. $15 \mathrm{O}$ PET measurement of blood flow and oxygen consumption in cold-activated human brown fat. J Nucl Med 2013;54:523-31.

49. Caterina MJ. Transient receptor potential ion channels as participants in thermosensation and thermoregulation. Am J Physiol Regul Integr Comp Physiol 2001;292:R64-76.

50. Yoneshiro T, Saito M. Transient receptor potential activated brown fat thermogenesis as a target of food ingredients for obesity management. Curr Opin Clin Nutr Metab Care 2013;16:625-31. 
51. Ma S, Yu H, Zhao Z, Luo Z, Chen J, Ni Y, et al. Activation of the cold-sensing TRPM8 channel triggers UCP1-dependent thermogenesis and prevents obesity. J Mol Cell Biol 2012;4:88-96.

52. Snitker S, Fujishima Y, Shen H, Ott S, Pi-Sunyer X, Furuhata Y, et al. Effects of novel capsinoid treatment on fatness and energy metabolism in humans: possible pharmacogenetic implications. Am J Clin Nutr 2009;89:45-50.

53. Yoneshiro T, Aita S, Kawai Y, Iwanaga T, Saito M. Nonpungent capsaicin analogs (capsinoids) increase energy expenditure through the activation of brown adipose tissue in humans. Am J Clin Nutr 2012;95:845-50.

54. Ludy MJ, Moore GE, Mattes RD. The effects of capsaicin and capsiate on energy balance: critical review and meta-analyses of studies in humans. Chem Senses 2012;37:103-21.
55. Bartelt A, Bruns OT, Reimer R, Hohenberg H, Ittrich H, Peldschus $\mathrm{K}$, et al. Brown adipose tissue activity controls triglyceride clearance. Nat Med 2011;17:200-5.

56. Nishio M, Yoneshiro T, Nakahara M, Suzuki S, Saeki K, Hasegawa $\mathrm{M}$, et al. Production of functional classical brown adipocytes from human pluripotent stem cells using specific hemopoietin cocktail without gene transfer. Cell Metab 2012;16:396-406.

57. Stanford KI, Middelbeek RJ, Townsend KL, An D, Nygaard EB, Hitchcox KM, et al. Brown adipose tissue regulates glucose homeostasis and insulin sensitivity. J Clin Invest 2013;123:215-23.

58. Chondronikola M, Volpi E, Børsheim E, Porter C, Annamalai P, Enerbäck S, et al. Brown adipose tissue improves whole-body glucose homeostasis and insulin sensitivity in humans. Diabetes 2014;63: 4089-99. 